\title{
ANÁLISE DAS ESTRUTURAS DE MERCADO DAS INDÚSTRIAS DE PAINÉIS DE MADEIRA (COMPENSADO, MDF E OSB) NO ESTADO DO PARANÁ
}

\author{
Cristiane de Loyola Eisfeld ${ }^{1}$, Ricardo Berger ${ }^{2}$ \\ 'Eng. Florestal, M.Sc., Klabin S/A, Telêmaco Borba, PR, Brasil - criseisfeld@ hotmail.com \\ ${ }^{2}$ Eng. Florestal, Dr., Depto. de Economia Rural e Extensão, UFPR, Curitiba, PR, Brasil - berger@bighost.com.br \\ Recebido para publicação: 12/03/2010 - Aceito para publicação: 10/11/2011
}

\begin{abstract}
Resumo
O presente trabalho teve como objetivo fazer uma análise das estruturas de mercado das indústrias de painéis de madeira (compensado, OSB e MDF) no estado do Paraná. Para analisar a situação atual da indústria de painéis, foi realizado um levantamento bibliográfico sobre as principais aplicações, a quantidade de empresas, o número de empregados, o consumo de madeira em tora, a capacidade nominal, a produção efetiva, o preço do painel, o valor e a quantidade de painel exportado e importado e o consumo aparente do segmento. As estruturas de mercado, entre os diferentes segmentos de painéis de madeira, foram analisadas através do Modelo Estrutura-Conduta-Desempenho (ECD), o qual mostrou que as indústrias de painéis de madeira reconstituída (MDF e OSB) são mais competitivas do que a indústria de painel compensado, por serem mais verticalizadas, de capital e tecnologia intensiva. $\mathrm{O}$ painel compensado é um produto de alto valor agregado e de qualidade, porém é de elevado custo quando comparado aos seus concorrentes. As perspectivas futuras da indústria paranaense de painéis de madeira indicam aumento no consumo de painéis reconstituídos e queda no consumo de painel compensado, devido à substituição que este vem sofrendo nos últimos anos.

Palavras-chave: Competitividade; estrutura de mercado; compensado; MDF e OSB.
\end{abstract}

\begin{abstract}
Market structure analysis of wood panels industries: plywood, MDF and OSB, in the State of Parana. This research aims to analyze market structure of wood panels industries: plywood, OSB and MDF, in the State of Parana. In order to analyze the current situation of wood panels industry in Parana it was improved a literature review based on: main applications, number of employees, number of companies, timber consumption, nominal capacity, effective production, price, value and quantity of exported and imported panels, and apparent consumption of those segments. The market structure, among the different wood panels types, was analyzed using the Model Structure - Conduct - Performance, which revealed that industries of reconstituted wood panels (MDF and OSB) are more competitive than the plywood industry, because their more vertical structure in relation to capital and intensive technology. Plywood is a high value product with high quality, but its cost compared to its competitors is higher. Prospects of the Parana State's wood panels industry indicate increasing consumption of reconstituted panels, and a decreasing consumption of plywood, due to its substitution in recent years. Keywords: Wood panels; competitiveness; market structure; plywood; MDF and OSB.
\end{abstract}

\section{INTRODUÇÃO}

O setor de produtos florestais compreende, genericamente, os segmentos de madeira em tora, madeira serrada, painéis de madeira, pasta de madeira e papel. A partir desses insumos, formam-se várias cadeias produtivas, destacando-se que, no caso dos setores de construção civil e moveleiro, os produtos de madeira serrada e os diversos painéis de madeira são bens substitutos entre si (REMADE, 2006).

Os painéis surgiram, principalmente, para atender a uma necessidade gerada pela escassez e pelo encarecimento da madeira maciça. A origem dos painéis retrata a necessidade de inovar a aplicação e o uso da madeira como matéria-prima. Surgiram como consequência da busca, feita pelo homem, por novos meios de utilizar e aproveitar, explorando ao máximo o potencial da madeira (TORQUATO, 2008). 
Os painéis de madeira dividem-se em três grandes grupos: compensados, aglomerados e chapas de fibras comprimidas. Os painéis estão consolidando posições de destaque no setor florestal e na economia brasileira, em decorrência do grande crescimento da produção na última década. Segundo os relatórios anuais do Banco Nacional do Desenvolvimento Econômico e Social (BNDES) (2008), os principais motivos desse crescimento foram a instalação de novas unidades produtoras, a busca de novas tecnologias de produção e a modernização do parque industrial.

A produção de compensado foi iniciada na década de 1940, atingindo níveis significativos a partir dos anos 70. O Brasil está posicionado entre os principais produtores mundiais de compensado. Sua ampla utilização justifica-se por suas características mecânicas e adaptabilidade a diversos usos. Entretanto, apesar da relativa importância para a nação, o segmento é bastante fragmentado. Entre os fatores limitadores, observamse algumas barreiras tecnológicas e custos elevados da matéria-prima (NOCE et al., 2007).

De acordo com Iwakiri (2005), desde o início da produção de compensado no final do século XIX, inúmeros tipos de painéis de madeira foram surgindo até o momento, sempre com a preocupação de buscar novos produtos com melhor relação custo/benefício para as aplicações específicas a que se destinam. No Brasil, a produção de painel de fibra teve início em 1955. A produção era voltada para painéis isolantes e chapas duras.

O painel de Fibras de Média Densidade (MDF) começou a ser produzido no Brasil em 1997, pela fábrica da Duratex, em Agudos (SP). Em seguida, começaram a operar as unidades da Tafisa (final de 1998), localizada em Piên, da Masisa (início de 2001), situada em Ponta Grossa e a da Arauco (final de 2001), localizada em Jaguariaíva, todas no estado do Paraná.

A produção do MDF usa como matéria-prima principal a madeira de eucalipto e pínus e apresenta como característica um processo seco com várias etapas. O MDF possui consistência que se aproxima à da madeira maciça. A maioria dos seus parâmetros físicos de resistência são superiores aos da madeira aglomerada, caracterizando-se também por possuir boa estabilidade dimensional e grande capacidade de usinagem (REMADE, 2007).

No Brasil, a produção do painel de tiras de madeira orientadas (OSB) é recente, data de 2001. A resistência desse painel é alta, embora não tanto quanto a da madeira sólida original, mas tão elevada quanto a dos compensados estruturais, aos quais substituem perfeitamente. O OSB tem a elasticidade da madeira convencional, mas é mais resistente mecanicamente. $\mathrm{O}$ seu custo é mais baixo, devido ao emprego de madeira de pequena dimensão, proveniente de florestas geridas de forma sustentável.

Durante o processo de produção de placas de OSB, é possível o melhor aproveitamento das toras de madeira. O OSB utiliza $96 \%$ da madeira contra $56 \%$ do compensado, o que permite otimizar o custo do produto, tornando-o ecologicamente mais eficiente. Dentre os usos do OSB, destacam-se pisos, divisórias, coberturas e obras temporárias, como, por exemplo, tapumes e alojamentos (REMADE, 2007).

Devido à importância desse segmento, especificamente no estado do Paraná, este estudo contemplou uma análise da competitividade entre as indústrias de painéis de madeira em compensado, MDF e OSB, através de um diagnóstico da estrutura de mercado, do grau de concentração e do desempenho dessas empresas.

\section{REVISÃO BIBLIOGRÁFICA}

\section{Concentração de mercado}

Concentração é a mais conhecida e utilizada forma de medida de poder de mercado. Ela é normalmente definida como a distribuição do número e tamanho de compradores e vendedores num mercado. As maiores questões concernentes à construção de índices de poder de mercado são: definições precisas da abrangência do mercado; escolha da unidade de medida a ser usada; decisão quanto a incluir nos cálculos todas ou somente algumas das empresas no mercado; o significado e a necessidade de se incluir alguma medida de dispersão do tamanho das firmas junto com o índice escolhido. Do ponto de vista teórico, raramente existe consenso sobre quais medidas de concentração e sobre quais indicadores (volume de vendas, total de receita etc.) devem ser usados para descrever a distribuição e a concentração das empresas que atuam num mercado (MARQUES, 1994).

Há, basicamente, dois indicadores para medir o grau de concentração de uma indústria, os quais procuram medir se o mercado de um determinado produto se aproxima mais de uma situação de competição perfeita, de um monopólio ou de algo intermediário (competições monopolísticas ou 
oligopolísticas). Esses dois indicadores são: índice de concentração das quatro maiores firmas e índice de Herfindahl-Hirschman (MENDES, 2009).

Os trabalhos publicados que utilizaram o índice de concentração das quatro maiores firmas e o índice de Herfindahl-Hirschman para analisar o mercado de produtos florestais, e que merecem destaque, são apresentados a seguir.

Amin et al. (2008) identificaram os municípios especializados nas atividades florestais e de madeira e mobiliário com potencial para desenvolver Arranjos Produtivos Locais (APL) no Pará. Os resultados indicaram a existência de nove municípios paraenses especializados, simultaneamente, nas duas atividades, podendo resultar em melhor estruturação desses APL para desenvolver localmente o Pará, via Polos de Desenvolvimento, mediante ações concretas de políticas públicas para o fortalecimento desses arranjos.

Silva et al. (2006) analisaram a estrutura e a concentração no consumo de madeira pelo setor moveleiro de Ubá/MG. Nesse trabalho verificou-se que o consumo de madeira das fábricas de móveis analisadas é caracterizado por um nível de concentração moderadamente baixo e que esse grupo de indústrias apresenta, em Ubá/MG, características de estrutura oligopolística.

Soares et al. (2005) verificaram a concentração do mercado internacional de madeira serrada, por meio dos índices de concentração e desigualdade de mercado e das estruturas de classificações de mercado. O indicador utilizado foi a exportação de 154 diferentes nações nos anos de 1997 e 1999, sendo constatadas a alta concentração e desigualdade do mercado internacional de madeira serrada e a evolução desses parâmetros no período analisado.

Coelho e Berger (2004) apresentaram estimativas do modelo de comércio internacional constantmarket-share, aplicado às exportações brasileiras de móveis para o período 1990/2000, com o objetivo de avaliar o desempenho das mesmas. Os resultados sugerem que o crescimento das exportações brasileiras de móveis foi determinado, principalmente, pela ação de fatores internos que afetam a competitividade.

Santana e Sá (2003) analisaram a evolução da concentração industrial e do poder de mercado das empresas de artefatos de madeira do estado do Pará. Os indicadores de concentração indicaram que esse segmento da indústria madeireira apresenta baixa concentração, operando numa estrutura de mercado próxima da concorrência pura.

\section{Estrutura, conduta e desempenho de mercado}

A análise das relações entre as empresas e seu ambiente competitivo (estrutura, formação de estratégias e eficiência) iniciou nos anos 30, com Mason, e depois foi aprofundado por Joe Bain na década de 60. Com base na estrutura de mercado, o economista Bain, em seu famoso livro Organização Industrial, apresentou o modelo denominado Estrutura-Conduta-Desempenho (ECD), também conhecido como análise estrutural, em que ele postula uma relação entre a estrutura de mercado, a conduta (comportamento) das firmas dentro do mercado e a eficiência (desempenho) delas (SANTANA; SÁ, 2003).

De acordo com o postulante do modelo ECD, há uma relação previsível entre seus três componentes, a tal ponto que, dada a estrutura, o padrão de conduta das firmas pode ser previsto, o que, por sua vez, leva a um padrão de desempenho previsível (MENDES, 2009).

$\mathrm{O}$ número de trabalhos publicados, tanto no âmbito nacional como internacional, que utilizaram o modelo ECD para análise estrutural de uma indústria, segmento ou setor, é crescente. Entretanto, são poucos os trabalhos que aplicam o modelo ECD ao estudo de produtos florestais e no setor agrícola em geral. Mesmo assim, alguns trabalhos merecem destaque.

Ferraz e Fernandes (2008), fundamentando-se no modelo Estrutura-Conduta-Desempenho, analisaram o mercado de distribuição de aço para a construção civil do sul de Minas Gerais. Grandes alterações na conduta dos distribuidores e a entrada de empresas vinculadas às usinas siderúrgicas têm alterado a dinâmica do setor, principalmente em resposta ao grau de concentração do mercado e ao importante desenvolvimento econômico do sul de Minas Gerais.

Montebello e Bacha (2007) analisaram alguns aspectos da estrutura e do desempenho da indústria brasileira de celulose, no período de 1980 a 2005, diante de sua crescente inserção no mercado internacional. Para tanto, à luz do paradigma Estrutura-Conduta-Desempenho, foram utilizados dados sobre produção, exportação e custo de produção de celulose brasileira e da produzida pelos seus principais concorrentes. Foi demonstrado que o Brasil apresentou expressivo desempenho no mercado internacional de celulose, mantendo e ganhando market share, causado por suas vantagens comparativas e por realizar significativas inovações tecnológicas tanto na área florestal quanto industrial. 
Carvalho et al. (2007), através da aplicação do modelo ECD, analisaram o desempenho competitivo das empresas da indústria de móveis de madeira do Pará. Os resultados mostraram que a maioria das empresas da indústria de móveis encontra-se em posição intermediária de desempenho competitivo, em função das limitações de fatores como a falta de mão de obra qualificada, baixo nível tecnológico, dificuldade de acesso ao crédito e baixo grau de integração vertical e horizontal da cadeia de suprimento.

Gama et al. (2007) determinaram a posição competitiva das empresas de móveis da Região Metropolitana de Belém, empregando o índice de desempenho competitivo. Com base nos resultados obtidos, concluiu-se que a maior parte das empresas de móveis da Região Metropolitana de Belém está operando em estádio intermediário de desenvolvimento competitivo, em razão da baixa magnitude dos escores fatoriais relativos a cada dimensão competitiva e/ou de sinal negativo.

Santana e Sá (2002) utilizaram o modelo Estrutura-Conduta-Desempenho para analisar a estrutura de mercado e a competitividade da cadeia produtiva de madeira na Amazônia. A taxa de concentração de mercado indicou um elevado grau de concentração da indústria nos estados do Acre, Amapá e Tocantins.

\section{MATERIAL E MÉTODOS}

O estudo das estruturas de mercado entre as indústrias de painéis de madeira (compensado, MDF e OSB) no estado do Paraná foi desenvolvido com base na análise da estrutura, no grau de concentração, na conduta e no desempenho das diversas empresas. A metodologia usada para essas análises é apresentada a seguir.

\section{Estrutura de mercado} básicas:

Para determinar a estrutura de um mercado florestal, devem-se observar algumas características

- o grau de concentração de mercado - representa o número de empresas e a participação de cada uma delas no total da produção e do consumo;

- o grau de diferenciação do produto - representa quão diferente o produto é aos olhos do consumidor;

- o protecionismo e as barreiras de mercado - representa restrições artificiais impostas pelas empresas no mercado com o objetivo de impedir a competitividade (BERGER; PADILHA JR., 2005).

A partir das características essenciais de estrutura de mercado, principalmente do número de empresas e da diferenciação do produto, os mercados de produtos florestais podem ser classificados como competitivos (concorrência pura e monopolística), pouco competitivos (oligopólios) e sem competição (monopólios).

Tabela 1. Principais estruturas de mercado pelo lado da oferta.

Table 1. Main market structures by supply side.

\begin{tabular}{|c|c|c|c|c|}
\hline Características & $\begin{array}{c}\text { Concorrência } \\
\text { pura }\end{array}$ & Monopólio & Oligopólio & $\begin{array}{l}\text { Concorrência } \\
\text { monopolística }\end{array}$ \\
\hline $\mathrm{N}^{\circ}$ de empresas & Muito grande & Só há uma empresa & Pequeno & Grande \\
\hline Produto & Homogêneo & $\begin{array}{c}\text { Não há substitutos } \\
\text { próximos }\end{array}$ & $\begin{array}{c}\text { Homogêneo ou } \\
\text { diferenciado }\end{array}$ & Diferenciado \\
\hline $\begin{array}{l}\text { Controle das } \\
\text { empresas sobre os } \\
\text { preços }\end{array}$ & $\begin{array}{c}\text { Não há } \\
\text { possibilidade } \\
\text { de manobras pelas } \\
\text { empresas }\end{array}$ & $\begin{array}{l}\text { As empresas têm grande } \\
\text { poder para manter } \\
\text { preços relativamente } \\
\text { elevados, } \\
\text { principalmente quando } \\
\text { não há intervenções do } \\
\text { governo. }\end{array}$ & $\begin{array}{l}\text { Dificultado pela } \\
\text { interdependência entre } \\
\text { as empresas, que } \\
\text { tendem a formar cartéis } \\
\text { controlando preços e } \\
\text { quotas de produção. }\end{array}$ & $\begin{array}{l}\text { Pouca margem de } \\
\text { manobra, devido à } \\
\text { existência de } \\
\text { substitutos próximos }\end{array}$ \\
\hline $\begin{array}{l}\text { Condições de } \\
\text { ingresso }\end{array}$ & Não há barreiras & $\begin{array}{c}\text { Há barreira ao acesso de } \\
\text { novas empresas }\end{array}$ & $\begin{array}{c}\text { Há barreira ao acesso de } \\
\text { novas empresas }\end{array}$ & Não há barreiras \\
\hline
\end{tabular}

A tabela 1 apresenta as principais formas alternativas de estruturas de mercado, considerando para tanto o número de empresas, o tipo de produto negociado, o controle das empresas sobre os preços e as condições de ingresso na indústria. 


\section{Concentração de mercado}

O grau de concentração de uma indústria procura medir se o mercado de um determinado produto se aproxima mais de uma situação de competição perfeita, de um monopólio ou de algo intermediário (competições monopolísticas ou oligopolísticas). O grau de concentração de mercado é medido através dos indicadores índice de concentração das quatro maiores firmas e índice de Herfindahl-Hirschman.

Para medir o grau de concentração das indústrias de painéis de madeira, foi utilizado o índice de concentração de quatro empresas, que é o percentual do valor das vendas registradas pelas quatro maiores firmas de uma indústria. $\mathrm{O}$ índice de concentração varia de quase $0 \%$, caso haja perfeita competição (em que estariam as propriedades rurais, na condição de empresa), até $100 \%$ no caso do monopólio. Esse índice é um bom indicador do grau de competitividade de um mercado. Por exemplo, um índice de concentração baixo indica um alto grau de competição, enquanto que um índice de concentração elevado evidencia a ausência de competição (CARVALHO; AGUIAR, 2005).

$\mathrm{O}$ grau de concentração de vendedores e compradores diz respeito ao número e tamanho de cada empresa no mercado. Acredita-se que uma indústria seja altamente concentrada quando apenas quatro empresas pertencentes a ela detiverem $75 \%$ ou mais da produção e do mercado de um determinado produto. Nesse caso, as quatro (ou menos) empresas tendem a agir em conluio e a comportarem-se como monopolistas. Se o índice de concentração das quatro maiores empresas for inferior a 40\%, é provável que elas concorram efetivamente entre si (MENDES, 2009).

\section{Estrutura, conduta e desempenho de mercado}

A ideia fundamental do modelo ECD é descrever as condições em que a dinâmica da estrutura de mercado, as regulamentações do governo e os demais fatores que influenciam o desempenho das empresas podem se transformar em ameaças, e como, a partir disso, criar oportunidades competitivas (SANTANA; SÁ, 2002).

$\mathrm{Na}$ análise de Scherer e Ross (1990), o desempenho é consequência da conduta dos vendedores e compradores em aspectos como práticas e políticas de determinação de preços, cooperação tácita entre firmas, linha de produtos e estratégias de divulgação, pesquisa e desenvolvimento, investimentos em técnicas de produção, táticas legais e assim por diante.

A conduta depende da estrutura predominante no mercado, caracterizada pela distribuição por número e tamanho dos ofertantes e demandantes (concentração), pela presença ou ausência de barreiras à entrada de novas firmas, pelas formas das curvas de custo e pelo grau de integração vertical das firmas, entre outras características.

A estrutura de um mercado é influenciada pelo que Scherer chama de características básicas. Essas características atuam tanto pelo lado da oferta quanto pelo da demanda. Pelo lado da oferta, são: a localização de matéria-prima, o grau de tecnologia, a durabilidade do produto, a relação valor/peso, atitudes nos negócios etc. Pelo lado da demanda, os fatores básicos são: elasticidade-preço da demanda, bens substitutos, taxa de crescimento da demanda, caráter cíclico e sazonal, métodos de compra, tipos diferentes de comercialização (LEITE, 1998).

O uso do modelo deve levar em conta, principalmente, os fluxos casuais que se originam da estrutura para a conduta e para o desempenho. Isso é explicado pelo fato de que a preocupação básica do modelo consiste na previsão da dimensão desempenho a partir da observação das chamadas condições básicas, da estrutura e da conduta (CARRAZZA; BACHA, 2003).

Como sugere o modelo teórico adotado, há influência da estrutura sobre a conduta e desta variável sobre o desempenho. Por conseguinte, pode-se omitir o estudo do componente intermediário e analisar de forma direta a relação entre estrutura e desempenho. O que favorece o surgimento desse modelo são as dificuldades na determinação das diferentes estratégias adotadas pelas firmas em diferentes períodos de tempo.

O estudo da estrutura e da conduta em um dado mercado é importante tanto por razões científicas quanto para fins de política pública. Segundo Leite (1998), a teoria econômica sugere que determinados tipos de estrutura e conduta conduzirão a um desempenho desejável.

Uma maneira de se analisar o efeito da estrutura sobre o desempenho consiste em tomar um corte de indústrias e verificar os efeitos do grau de concentração sobre a taxa de lucro. $\mathrm{O}$ autor sugere ainda que um elevado nível de concentração implicaria o surgimento de lucros elevados. Isto é, um nível de concentração elevado teria como consequência a obtenção dos resultados esperados ou planejados. 


\section{RESULTADOS E DISCUSSÃO}

Para analisar a estrutura de mercado e o desempenho das indústrias de painéis de madeira no estado do Paraná, foram levantados dados sobre o número de empresas, o consumo de madeira em tora, a capacidade nominal e a produção efetiva, o preço da matéria-prima e a exportação, os quais são apresentados a seguir.

\section{Número de empresas}

O mercado brasileiro de compensados atualmente é composto por aproximadamente 300 empresas, as quais, na sua maioria, estão concentradas na região Sul do país. No estado do Paraná, no ano de 2007, estavam localizadas 118 empresas, cerca de $40 \%$ das indústrias de painéis de compensado do Brasil. O número de empresas no estado do Paraná atingiu o máximo no ano de 2004, coincidindo com a elevação do consumo de madeiras em tora, da produção efetiva e da exportação no Paraná.

O estado do Paraná apresenta também a maior concentração de indústrias de aglomerado e MDF e também possui a única unidade de OSB do Brasil. Existem quatro linhas de produção de painéis aglomerados, sendo duas situadas na Região Metropolitana de Curitiba, uma em Ponta Grossa e uma no município de Piên (ASSOCIAÇÃO BRASILEIRA DA INDÚSTRIA DE PAINÉIS DE MADEIRA (ABIPA) (2008). A empresa produtora de OSB está localizada em Ponta Grossa (Masisa). Já o MDF é produzido por três empresas, localizadas nas cidades de Piên (Tafisa), Ponta Grossa (Masisa) e Jaguariaíva (Arauco).

Deve-se observar que uma empresa pode utilizar a mesma instalação industrial e fabricar mais de um tipo de painel reconstituído, como é o caso da empresa que fabrica OSB, MDF e aglomerado na mesma fábrica em Ponta Grossa. Dessa forma, é quantificado o número de linhas de produção em específico e não necessariamente o número de fábricas existentes no estado.

\section{Consumo de madeira em tora}

As fábricas de madeira compensada utilizam madeiras em toras de diâmetros acima de $25 \mathrm{~cm}$, principalmente para fabricação de compensados multilaminados. Já as fábricas de painéis reconstituídos utilizam como fonte de matéria-prima árvores de pequeno diâmetro, resíduos da exploração florestal e alguns resíduos industriais (cavaco, por exemplo).

O segmento de painel compensado demandou em 2007 aproximadamente 3,8 milhões de $\mathrm{m}^{3} \mathrm{de}$ madeira em tora, mesmo valor consumido pelo segmento de painéis reconstituídos (aglomerado, MDF e OSB), conforme observado na figura 1. No contexto geral, o Paraná teve uma evolução no seu consumo total de madeira para o segmento de painéis, passando de 3 milhões de $\mathrm{m}^{3}$, em 1997, para aproximadamente 7,6 milhões de $\mathrm{m}^{3} \mathrm{em} 2007$, o que representa um aumento de $220 \%$ em um período de 10 anos.

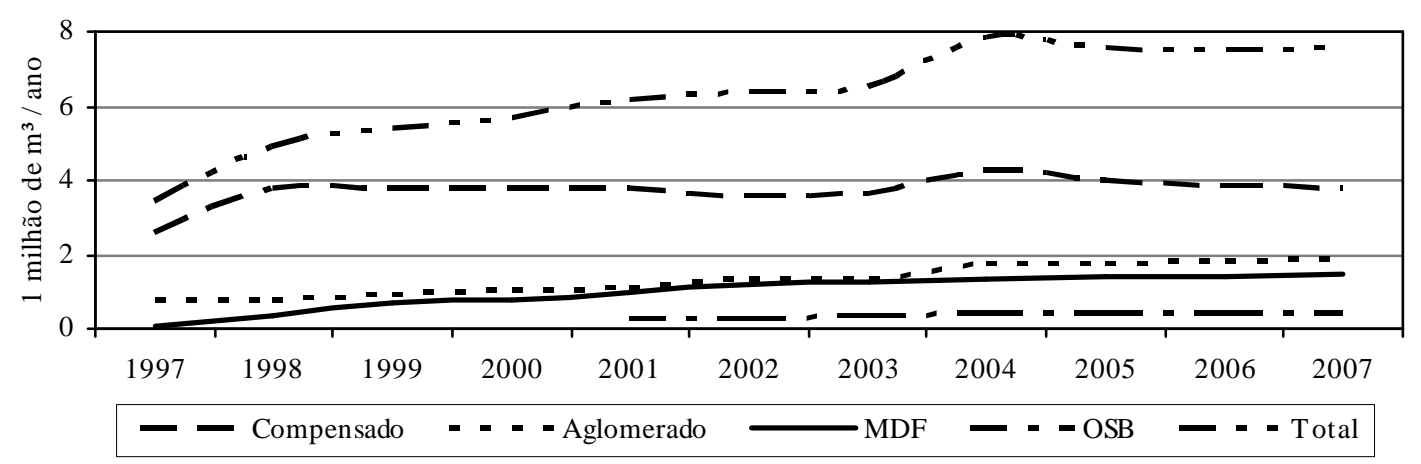

Figura 1. Evolução do consumo de madeira em tora para a fabricação de painéis no Paraná.

Figure 1. Consumption of wood in logs for manufacture of panels in Parana State.

Fonte: Berger et al., 2007.

\section{Produção efetiva}

A produção brasileira de painéis de madeira, no ano de 2007, atingiu cerca de 6,7 milhões de $\mathrm{m}^{3}$, um aumento de aproximadamente $250 \%$ do total produzido em 1997, o que corresponde a um crescimento médio de $13 \%$ ao ano (Figura 2). Analisando-se o ano de 2006, o estado do Paraná produziu 
cerca de 4 milhões de $\mathrm{m}^{3}$ de painéis (aglomerado, MDF, OSB e compensado), o que representa aproximadamente $70 \%$ do total produzido pelo Brasil nesse ano (STCP, 2009).

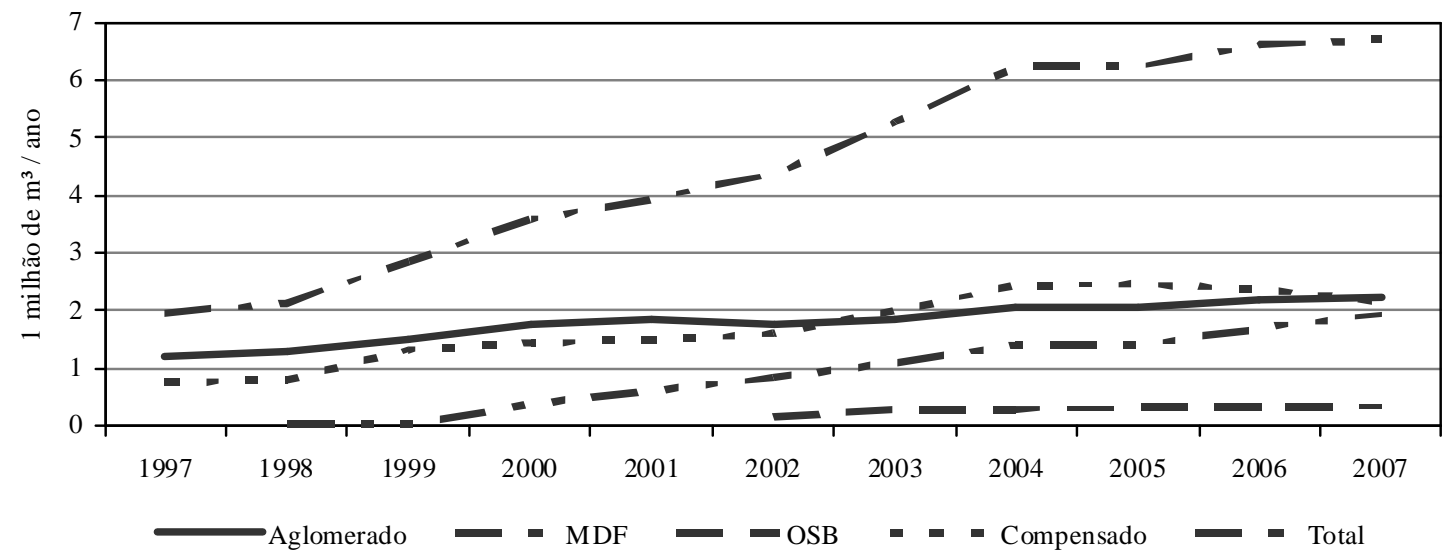

Figura 2. Evolução da produção brasileira de painéis de madeira.

Figure 2. Brazilian wood panels production evolution.

Fonte: STCP, 2009.

O parque fabril paranaense produziu, em 2008, cerca de 2 milhões de metros cúbicos de madeira compensada. Durante o ano de 2004, observou-se um significativo aumento na produção efetiva, verificado também nas séries históricas sobre o número de empresas e consumo de toras. Em termos gerais, a produção efetiva de painel compensado deve ser analisada em dois períodos. Entre o ano de 1997 e 2005, o crescimento médio anual foi de $16 \%$, ou $228 \%$ de variação percentual. Do ano de 2005 até 2008 , ocorreu uma redução na produção paranaense de compensado da ordem de $29 \%$, ou seja, uma redução anual de $10,8 \%$.

Já a produção de painéis reconstituídos (aglomerado, MDF e OSB), no estado do Paraná, em 1997, era de 500 mil metros cúbicos, passando para 2,1 milhões de metros cúbicos em 2006. A taxa de utilização da capacidade nominal do segmento da madeira reconstituída em geral foi superior a $60 \%$, sendo que, após o ano de 2000, torna-se superior a 70\%, com tendência de aumento.

O aglomerado teve um melhor aproveitamento da capacidade nominal no período de 2000 a 2002, sendo superior a $80 \%$. A utilização da capacidade nominal do aglomerado passou de $57 \%$ em 1997 para $78 \%$ em 2006, o que representa um aumento de $40 \%$. Esse aumento se deve principalmente a ajustes internos nas linhas de produção já existentes no estado.

Para o MDF ocorreu a entrada de novas linhas de produção, gerando um aumento na capacidade nominal. Apenas em 2003 ocorreu uma retração da utilização da capacidade nominal, ficando abaixo dos $80 \%$ de sua capacidade. A taxa de utilização da capacidade nominal do segmento foi em média de $88 \%$, durante o período de 1998 a 2006.

A utilização da capacidade nominal do OSB apresenta-se praticamente estável desde o ano de 2004, pelo fato de que esse tipo de painel está restrito a apenas uma linha de produção.

Após o ano de 2004, tanto a produção de aglomerados quanto a de MDF passaram por uma redução na velocidade de crescimento de suas produções efetivas. Entretanto, nesse mesmo ano, a produção de MDF superou a produção efetiva de aglomerado (Figura 3).

Em 2006 o Paraná contou com uma produção de painéis reconstituídos que ultrapassou os 2,1 milhões de metros cúbicos ao ano, o que representa um aumento de aproximadamente $350 \%$, quando comparado ao ano de 1997. Nesse mesmo ano, o segmento de MDF operou com uma capacidade de $97 \%$, o de aglomerado com $78 \%$ e o de OSB com $91 \%$, resultando em uma utilização média da capacidade nominal de $79 \%$ (Tabela 2).

\section{Preço das toras de pínus no mercado brasileiro}

A matéria-prima utilizada nas indústrias de compensado são toras de madeira proveniente de reflorestamentos, principalmente de pínus, com diâmetro acima de $25 \mathrm{~cm}$ (REMADE, 2006). A evolução do preço real das toras de pínus no mercado nacional é apresentada na figura 4. 


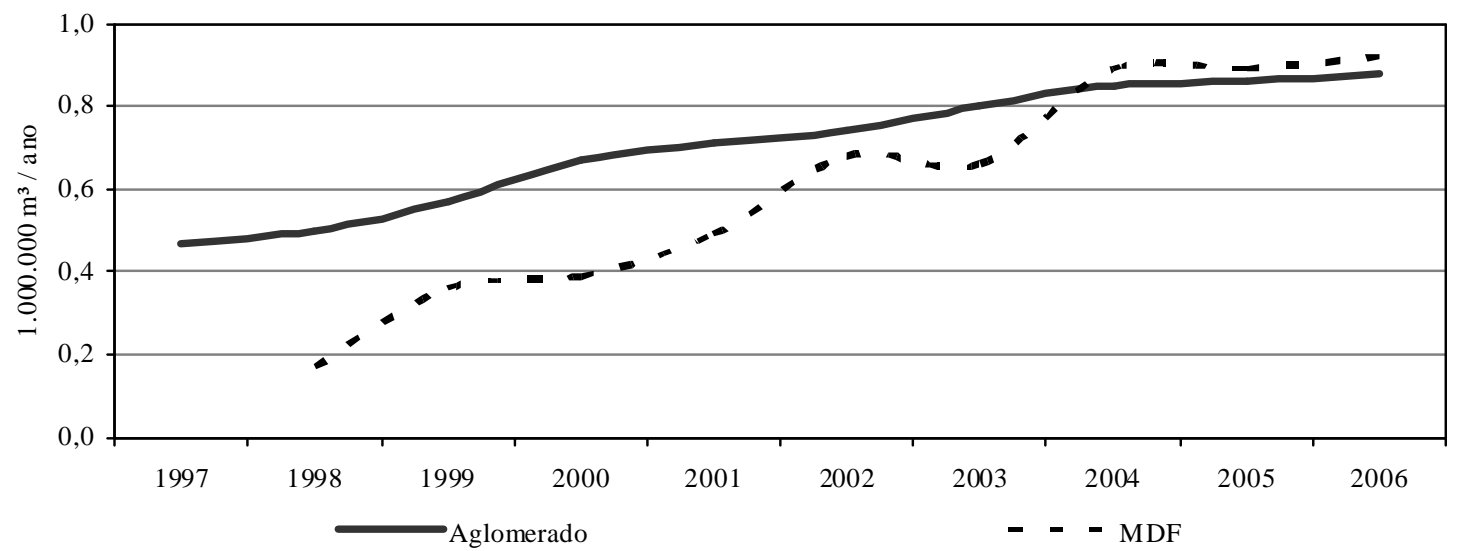

Figura 3. Evolução da produção efetiva de aglomerado e MDF no Paraná.

Figure 3. Evolution of effective production for MDP and MDF in Parana State.

Fonte: Berger et al., 2007.

Tabela 2. Taxa de utilização da capacidade nominal das empresas de aglomerado, MDF e OSB no Paraná.

Table 2. Utilization rate of nominal capacity of MDP, MDF and OSB in Parana State.

\begin{tabular}{|c|c|c|c|}
\hline ANO & $\begin{array}{l}\text { Produção efetiva } \\
\left(1 \text { milhão de } \mathbf{m}^{3}\right)\end{array}$ & $\begin{array}{l}\text { Produção nominal } \\
\left(1 \text { milhão de } \mathbf{m}^{3}\right)\end{array}$ & $\begin{array}{c}\text { Utilização da capacidade } \\
\text { nominal }(\%)\end{array}$ \\
\hline 1997 & 0,47 & 0,83 & 57 \\
\hline 1998 & 0,67 & 1,08 & 62 \\
\hline 1999 & 0,93 & 1,21 & 77 \\
\hline 2000 & 1,06 & 1,24 & 85 \\
\hline 2001 & 1,40 & 1,60 & 88 \\
\hline 2002 & 1,62 & 1,94 & 84 \\
\hline 2003 & 1,71 & 2,15 & 80 \\
\hline 2004 & 2,04 & 2,40 & 85 \\
\hline 2005 & 2,05 & 2,40 & 85 \\
\hline 2006 & 2,12 & 2,44 & 87 \\
\hline
\end{tabular}

Fonte: Berger et al., 2007.

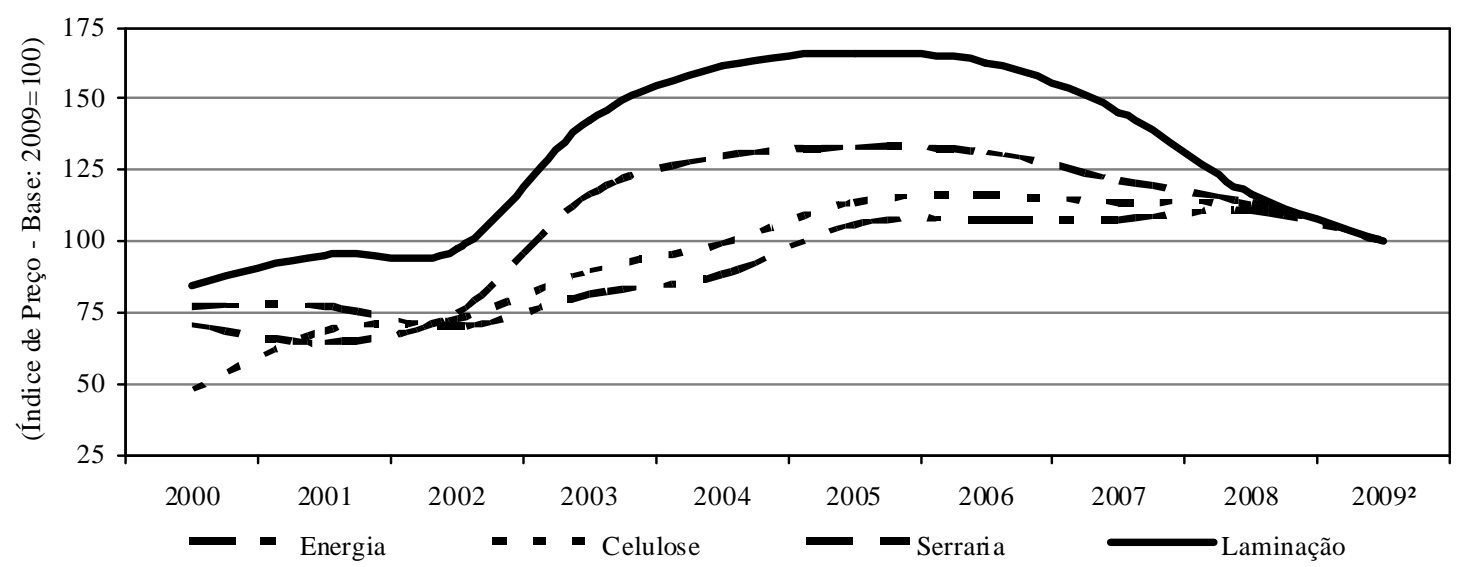

Figura 4. Evolução do preço real das toras de pínus no mercado brasileiro.

Figure 4. Real price evolution for pinus log in Brazilian market.

${ }^{1}$ Deflacionados pelo IPCA; ${ }^{2}$ Dados compilados de janeiro a agosto/2009

Fonte: STCP, 2009. 
A evolução do preço real das toras de pínus mostra que, entre 2002 e 2005, o crescimento foi de aproximadamente $70 \%$ para a tora destinada à laminação. Esse aumento foi impulsionado, principalmente, pela valorização cambial ocorrida nesse período. Após 2005, o preço real da tora de pínus para laminação veio caindo, e em 2009 voltou aos patamares de 2002. Essa redução do preço real das toras de pínus para laminação se deve principalmente à redução da demanda de compensado pelos Estados Unidos, principal importador.

\section{Preço dos painéis de madeira no mercado brasileiro}

O painel aglomerado concorre diretamente com o MDF, no segmento mobiliário. A evolução do preço desses dois produtos apresenta uma tendência similar, entretanto essa diferença vem caindo, visto que a demanda por esses painéis vem crescendo (Figura 5).

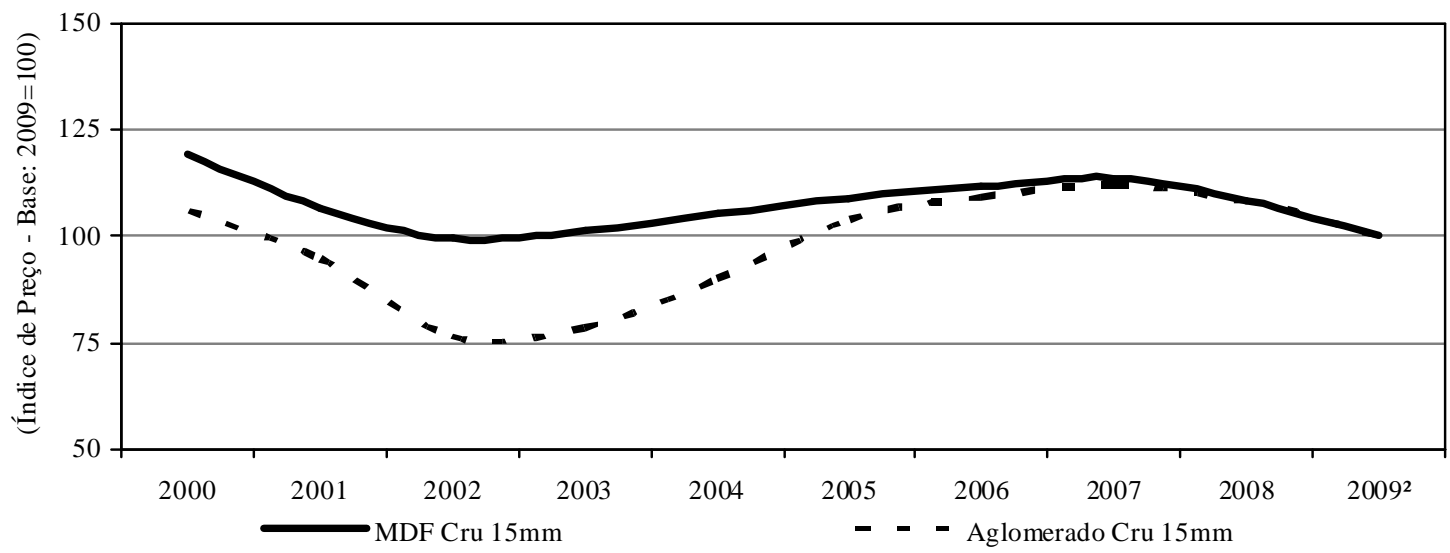

Figura 5. Evolução do preço real do aglomerado e do MDF no mercado brasileiro.

Figure 5. Real price evolution for MDP and MDF in Brazilian market.

${ }^{1}$ Deflacionados pelo IPCA; ${ }^{2}$ Dados compilados de janeiro a agosto/2009.

Fonte: STCP, 2009.

O painel compensado de pínus concorre diretamente com o OSB, no segmento da construção civil. A evolução do preço desses dois produtos apresenta a mesma tendência, entretanto o OSB é aproximadamente $30 \%$ mais barato que o painel compensado (Figura 6).

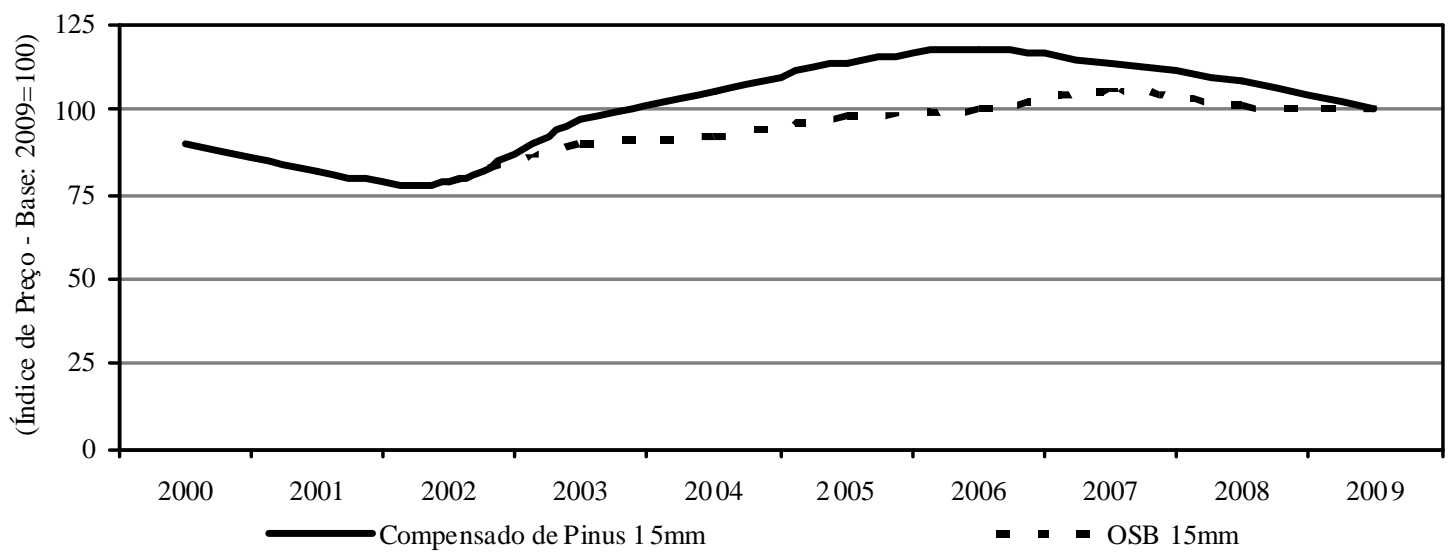

Figura 6. Evolução do preço real do compensado de pínus e do OSB no mercado brasileiro.

Figure 6. Real price evolution for pinus plywood and OSB in Brazilian market.

${ }^{1}$ Deflacionados pelo IPCA; ${ }^{2}$ Dados compilados de janeiro a agosto/2009.

Fonte: STCP, 2009. 


\section{Exportação dos painéis de madeira}

No conjunto, os segmentos de painéis de partícula, de fibra e compensado exportaram, em 2008, US\$ 760 milhões, representando uma queda de $13 \%$ sobre os US\$ 869 milhões no ano anterior (Figura 7).

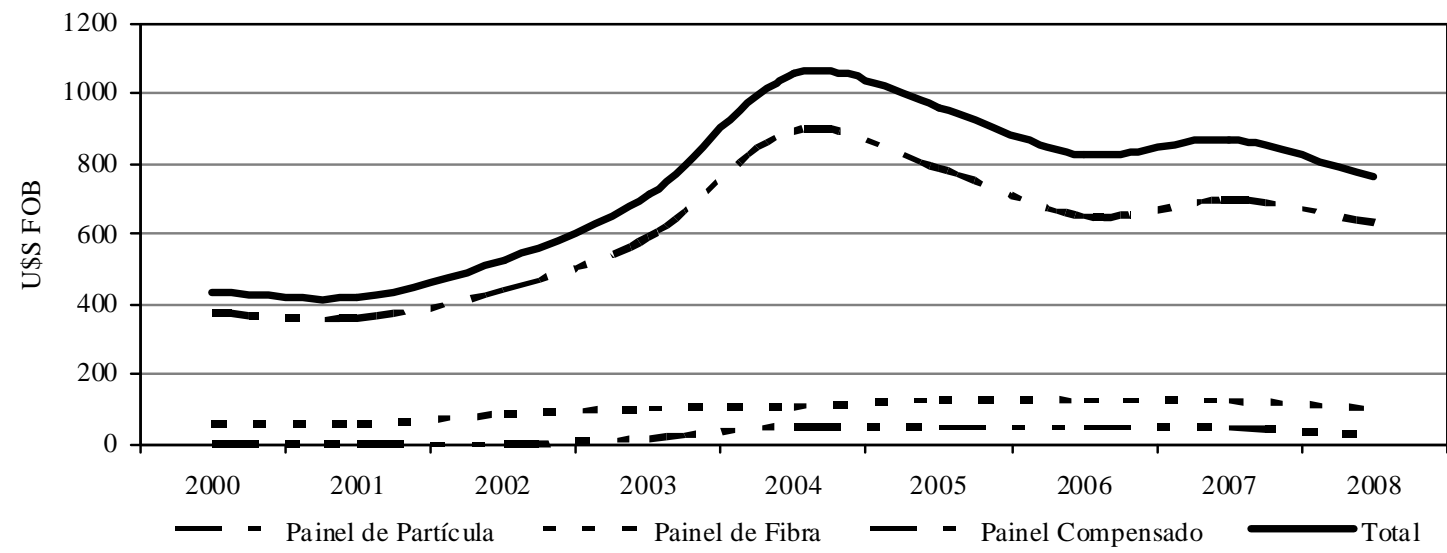

Figura 7. Evolução da exportação brasileira de painéis de madeira.

Figure 7. Brazilian exports evolution for wood panels.

Fonte: SECEX, 2009.

Observando o comportamento do gráfico, nota-se que, até o ano de 2004, a exportação brasileira de painéis de madeira foi crescente. Nesse período, tanto a quantidade quanto o volume exportado cresceram cerca de $140 \%$. Em 2008, devido principalmente à desvalorização cambial, a exportação brasileira caiu, retornando aos patamares observados em 2003.

Nesse item, o maior estado exportador é o Paraná, detendo 55\% do total exportado. Santa Catarina é o segundo estado exportador, com 20\%, e São Paulo figura como terceiro, com 10\%. Esses três estados juntos detêm $85 \%$ do total da exportação brasileira de painéis de madeira.

\section{Estrutura de mercado}

Com relação à estrutura de mercado das indústrias de painéis (compensado, MDF e OSB), é possível inferir que a indústria de compensado pode ser considerada como um mercado de competição monopolística, em que existe um grande número de empresas, em que nenhum vendedor ou comprador em particular pode influenciar o preço e existe certo grau de diferenciação dos produtos (Tabela 3). Uma das principais características da indústria de compensados é a inexistência de expressivas barreiras à entrada, especialmente em relação ao volume de investimento requerido. Também é interessante ressaltar algumas desvantagens relativas ao tamanho das empresas produtoras de compensado no Brasil, como a pequena capacidade de investimento, o não alcance de determinados mercados por limitações na produção e a não ocorrência de sustentabilidade da base florestal, devido ao pequeno investimento das empresas na formação de florestas.

A indústria de painel MDF é considerada um oligopólio em que existe um pequeno número de empresas e o produto pode ser homogêneo ou não. Segundo Bacha et al. (2007), a indústria de MDF pode ser considerada um oligopólio homogêneo, sem muita diferenciação entre os produtos.

A indústria de painel OSB é considerada um monopólio, haja vista que existe apenas uma empresa fabricando um determinado produto no mercado paranaense. A única empresa produtora de OSB no Brasil é a Masisa, em Ponta Grossa, no Paraná, com capacidade anual de produção de 200 mil metros cúbicos.

\section{Concentração de mercado}

O índice de concentração de quatro empresas varia de $0 \%$, quando existe perfeita competição, até $100 \%$ no caso do monopólio. Esse índice é um bom indicador do grau de competitividade de um mercado. No caso da indústria de OSB, pode-se afirmar que o grau de concentração é de $100 \%$, devido ao fato de existir apenas uma indústria produzindo um determinado produto. 
Tabela 3. Caracterização das estruturas de mercado dos painéis.

Table 3. Characterization of panel market structure.

\begin{tabular}{lccc}
\hline Características & Painel OSB & Painel MDF & Painel compensado \\
\hline Estrutura de mercado & Monopólio & Oligopólio & $\begin{array}{c}\text { Concorrência } \\
\text { monopolística }\end{array}$ \\
\hline Concentração de mercado & $100 \%$ & $87,5 \%$ & $<40 \%$ \\
\hline $\mathrm{N}^{\mathbf{0}}$ de empresas & Só há uma empresa & Apenas três empresas & 118 Empresas \\
\hline Produto & Homogêneo & Diferenciado & Diferenciado \\
\hline $\begin{array}{l}\text { Controle das empresas } \\
\text { sobre os preços }\end{array}$ & Grande poder & $\begin{array}{c}\text { Dificultado pela } \\
\text { interdependência entre as } \\
\text { empresas }\end{array}$ & $\begin{array}{c}\text { Pouca margem de } \\
\text { manobra, devido à } \\
\text { existência de substitutos } \\
\text { próximos }\end{array}$ \\
\hline $\begin{array}{l}\text { Condições de ingresso na } \\
\text { indústria }\end{array}$ & $\begin{array}{c}\text { Há barreira ao acesso de } \\
\text { novas empresas }\end{array}$ & $\begin{array}{c}\text { Há barreira ao acesso de } \\
\text { novas empresas }\end{array}$ & Não há barreiras \\
\hline
\end{tabular}

O grau de concentração diz respeito ao número e tamanho de cada empresa no mercado. Acredita-se que uma indústria seja altamente concentrada quando apenas quatro empresas pertencentes a ela detiverem $75 \%$ ou mais da produção e de mercado de um determinado produto.

Isso ocorre na indústria paranaense de MDF, onde apenas 3 empresas são responsáveis por toda a produção desse tipo de produto no estado. Nesse caso, as três empresas tendem a agir em conluio e a comportar-se como monopolistas.

O conluio é um acordo entre duas ou mais empresas para restringir o nível de produção, com o objetivo de aumentar preços ou lucros. Esse tipo de conluio é denominado cartel. A produção brasileira de MDF iniciou-se em 1997 e, em 2005, atingiu o volume de 1,4 milhão de metros cúbicos. Há no Brasil seis empresas. As quatro maiores (Duratex, Tafisa, Arauco e Masisa) detêm 87,5\% da capacidade instalada (BACHA et al., 2007).

No caso do painel compensado, o índice de concentração das quatro maiores empresas (Sudati, Guararapes, Lavrasul e Berneck) é inferior a 40\%, o que significa que elas concorrem efetivamente entre si. O Grupo Sudati possui aproximadamente $85 \%$ da produção destinada ao mercado externo e é responsável por aproximadamente $30 \%$ das exportações de placas de compensados do Brasil. A Guararapes Indústria de Compensado, maior exportadora desse setor, está atualmente fabricando 25 mil metros cúbicos por mês, o que representa $62,5 \%$ da sua capacidade, de 40 mil metros cúbicos.

\section{CONCLUSÕES}

O presente trabalho tinha por objetivo fazer uma análise das estruturas de mercado das indústrias de painéis de madeira (compensado, OSB e MDF) no estado do Paraná. Com base na análise dos resultados para as indústrias de painéis (compensado, MDF e OSB), chegaram-se às seguintes conclusões:

- Compensado: utilizado por sua qualidade superior, quando comparado com outros produtos mais baratos utilizados para a sua substituição, tal como o OSB. Porém é considerado um produto em fim de linha, e em alguns nichos de mercado vem sendo substituído por outros painéis. O consumo mundial é declinante, uma vez que vem sofrendo escassez de matéria-prima e elevação dos custos de produção;

- MDF: boa estabilidade, usinagem e alta resistência criam oportunidades para que ele possa ser usado como uma alternativa ao aglomerado e à madeira maciça para várias aplicações, como armários e molduras;

- OSB: pode ser obtido a partir de madeiras provenientes de desbastes e de troncos finos e tortuosos, bem como de espécies de menor valor comercial. Concorre diretamente com o compensado, que apresenta indicações para os mesmos tipos de uso, entretanto requer toras de alta qualidade para a sua manufatura e, por isso, é de custo relativamente superior.

\section{REFERÊNCIAS}

AMIN, M. M.; SANTANA, A. C.; FILGUEIRAS, G. C.; MENDES, F. A. T. A concentração espacial da atividade florestal no estado do Pará. In: XLVI Congresso da Sociedade Brasileira de Economia, Rio Branco, Acre, 2008. 
ASSOCIAÇÃO BRASILEIRA DA INDÚSTRIA DE PAINÉIS DE MADEIRA (ABIPA). Nossas unidades industriais. Disponível em: 〈http://www.abipa.org.br/industrias.php>. Acesso em: 07/2008b.

BACHA, C. J. C.; BRUGNARO, R.; CAMARGO, G. B. C. A indústria de painéis. In. Agroanalysis Revista de Agronegócios da FGV. v. 27, 2007.

BANCO NACIONAL DO DESENVOLVIMENTO ECONÔMICO E SOCIAL (BNDES). Setorial: Painéis de madeira no Brasil: panorama e perspectivas. Rio de Janeiro, n. 27, p. 121 - 156, mar. 2008.

BERGER, R.; PADILHA JR., J. B. Economia Florestal. (Apostila da Disciplina de Economia Florestal) Setor de Ciências Agrárias, Universidade Federal do Paraná, 2005.

BERGER, R.; SANTOS, A. J.; TIMOFEICZYK JR., R. Oferta e demanda de madeira para fins industriais no estado do Paraná. Secretaria de Estado da Ciência, Tecnologia e Ensino Superior, CuritibaPR, 2007.

CARRAZZA, L. C.; BACHA, C. J. C. Evolução e estrutura da indústria de papéis no Brasil: Período de 1965 a 2002, 2003. Disponível em: <http://www.sober.org.br/palestra/12/04O245.pdf>. Acesso em: $10 / 2009$.

CARVALHO, D. F.; SANTANA, A. C. de; NOGUEIRA, A. K. M.; MENDES, F. A. T.; CARVALHO, A. C. Análise do desempenho competitivo da indústria de móveis de madeira do estado do Pará. Amazônia Ciência \& Desenvolvimento, Belém, v. 2, n. 4, 2007.

CARVALHO, L. H.; AGUIAR, D. R. D. Concentração de mercado e poder de monopsônio na indústria brasileira de esmagamento de soja. Revista de Economia e Agronegócio, v. 3, n. 3, 2005.

COELHO, M. R. F.; BERGER, R. Competitividade das exportações brasileiras de móveis no mercado internacional: uma análise segundo a visão desempenho. Revista FAE, Curitiba, v. 7, n. 1, p. 51 - 65, 2004.

FERRAZ, H. V. D.; FERNANDES, E. A. Análise do mercado de aço para a construção civil no sul de Minas Gerais. Revista Economia e Desenvolvimento, n. 20, 2008.

GAMA, Z. J. C.; SANTANA, A. C. de; MENDES, F. A. T.; KHAN, A. S. Índice de desempenho competitivo das empresas de móveis da Região Metropolitana de Belém. Revista de Economia e Agronegócio, v. 5, n. 1, 2007.

IWAKIRI, S. Painéis de madeira reconstituída. FUPEF. Curitiba, 2005.

LEITE, A. L. S. Concentração e desempenho competitivo no complexo industrial de papel e celulose 19871996. Dissertação (Mestrado) - Universidade Federal de Santa Catarina, 1998.

MARQUES, P. V. Contribuição ao estudo da organização agroindustrial: o caso da indústria de frango de corte no estado de São Paulo. Scientia Agrícola, Piracicaba, São Paulo, v. 51, n. 1, p. 8 - 16, 1994.

MENDES, J. T. G. Economia: fundamentos e aplicações. São Paulo, Pearson Prentice Hall, 2. ed., 2009.

MONTEBELLO, A. E. S.; BACHA, C. J. C. Estrutura de mercado e desempenho da indústria brasileira de celulose: período de 1980 a 2005. In: PESQUISA \& DEBATE, SP, v. 18, n. 1(31) p. 83 - 104, 2007.

NOCE, R.; CARVALHO, R. M. M. A.; CANTO, J. L.; SILVA, M. L.; MENDES, L. M. Medida de desigualdade do mercado internacional de compensado. Revista Cerne, v. 13, n. 1, p. 107 - 110, 2007.

REMADE. Revista da Madeira: Diversidade de produção amplia usos no setor. Edição ${ }^{\circ}{ }^{95}$. Abril, 2006.

Revista da Madeira: Painel de OSB oferece maior resistência para uso em estruturas. Edição no 108 . Outubro, 2007.

SANTANA, A. C.; SÁ, J. A. S. Competitividade e desempenho da cadeia produtiva da madeira da região norte. In: XXII Encontro Nacional de Engenharia de Produção, Curitiba/PR, 2002.

Concentração e poder de mercado das empresas de artefatos de madeira do estado do Pará. In: XXIII Encontro Nacional de Engenharia de Produção, Ouro Preto/MG, 2003. 
SCHERER, F. M.; ROSS, D. Industrial market structure and economic performance. EUA: Houghton Mifflin Company, 1990.

SECRETARIA DE COMÉRCIO EXTERIOR (SECEX). Sistema Alice. Disponível em: <http:// aliceweb.desenvolvimento.gov.br/default.asp>. Acesso em: 05/2009.

SILVA, M. L.; SOARES, T. S.; NISHI, M. H.; OLIVEIRA, P. R. S. Concentração no consumo de madeira e estrutura de mercado do setor moveleiro do município de Ubá/MG. In: Revista Científica Eletrônica de Engenharia Florestal, Faculdade de Agronomia e Engenharia Florestal de Garça, n. 7, 2006.

SOARES, T. S.; NOCE, R.; SILVA. M. L.; CARVALHO, R. M. M. A. Concentração das exportações no mercado internacional de madeira serrada. In: Revista Árvore, Viçosa/MG, v. 29, n. 3, p. 431 - 437, 2005.

STCP Engenharia de Projetos Ltda. Banco de Dados. Curitiba/PR, 2009.

TORQUATO, L. P. Caracterização dos painéis MDF comerciais produzidos no Brasil. Curitiba, 2008. 93 p. Dissertação (Mestrado em Ciências Florestais) - Setor de Ciências Agrárias, Universidade Federal do Paraná.

VASCONCELlOS, M. A. S.; GARCIA, M. E. Fundamentos de economia. 2. ed. São Paulo, Editora Saraiva, 2005, p. 81. 
FLORESTA, Curitiba, PR, v. 42, n. 1, p. 21 - 34, jan./mar. 2012 Eisfeld, C.de L.; Berger, R. 